\title{
Grapevine Rpv3-, Rpv10- and Rpv12- mediated defense responses against Plasmopara viticola and the impact of their deployment on fungicide use in viticulture
}

\author{
Chantal Wingerter ${ }^{1,2 \dagger}$, Birgit Eisenmann ${ }^{1 \dagger}$, Patricia Weber ${ }^{2}$, lan Dry ${ }^{3}$ and Jochen Bogs $s^{1,4^{*}}$ (D)
}

\begin{abstract}
Background: The high susceptibility of European grapevine cultivars (Vitis vinifera) to downy mildew (Plasmopara viticola) leads to the intensive use of fungicides in viticulture. To reduce this input, breeding programs have introgressed resistance loci from wild Vitis species into $V$. vinifera, resulting in new fungus-resistant grapevine cultivars (FRC). However, little is known about how these different resistance loci confer resistance and what the potential reduction in fungicide applications are likely to be if these FRCs are deployed. To ensure a durable and sustainable resistance management and breeding, detailed knowledge about the different defense mechanisms mediated by the respective Rpv (Resistance to P. viticola) resistance loci is essential.
\end{abstract}

Results: A comparison of the resistance mechanisms mediated by the Rpv3-1, Rpv10 and/or Rpv12-loci revealed an early onset of programmed cell death (PCD) at 8 hours post infection (hpi) in Rpv12-cultivars and $12 \mathrm{hpi}$ in Rpv10-cultivars, whereas cell death was delayed in Rpv3-cultivars and was not observed until 28 hpi. These temporal differences correlated with an increase in the trans-resveratrol level and the formation of hydrogen peroxide shortly before onset of PCD. The differences in timing of onset of Rpv-loci specific defense reactions following downy mildew infection could be responsible for the observed differences in hyphal growth, sporulation and cultivar-specific susceptibility to this pathogen in the vineyard. Hereby, Rpv3- and Rpv12/Rpv3-cultivars showed a potential for a significant reduction of fungicide applications, depending on the annual P. viticola infection pressure and the Rpv-loci. Furthermore, we report on the discovery of a new P. viticola isolate that is able to overcome both Rpv3-and Rpv12-mediated resistance.

Conclusion: This study reveals that differences in the timing of the defense reaction mediated by the Rpv3-, Rpv10and Rpv12-loci, result in different degrees of natural resistance to downy mildew in field. Vineyard trials demonstrate that Rpv12/Rpv3- and Rpv3-cultivars are a powerful tool to reduce the dependence of grape production on fungicide applications. Furthermore, this study indicates the importance of sustainable breeding and plant protection strategies

\footnotetext{
*Correspondence: jochen.bogs@dlr.rlp.de

${ }^{\dagger}$ Chantal Wingerter and Birgit Eisenmann contributed equally to this

work.

${ }^{4}$ Technische Hochschule Bingen, 55411 Bingen am Rhein, Germany

Full list of author information is available at the end of the article
}

(C) The Author(s) 2021. Open Access This article is licensed under a Creative Commons Attribution 4.0 International License, which permits use, sharing, adaptation, distribution and reproduction in any medium or format, as long as you give appropriate credit to the original author(s) and the source, provide a link to the Creative Commons licence, and indicate if changes were made. The images or other third party material in this article are included in the article's Creative Commons licence, unless indicated otherwise in a credit line to the material. If material is not included in the article's Creative Commons licence and your intended use is not permitted by statutory regulation or exceeds the permitted use, you will need to obtain permission directly from the copyright holder. To view a copy of this licence, visit http://creativecommons.org/licenses/by/4.0/. The Creative Commons Public Domain Dedication waiver (http://creativeco mmons.org/publicdomain/zero/1.0/) applies to the data made available in this article, unless otherwise stated in a credit line to the data. 
based on resistant grapevine cultivars to reduce the risk of new P. viticola isolates that are able to overcome the respective resistance mechanism.

Keywords: Disease resistance, Downy mildew, Grapevine, Rpv12, Rpv10, Rpv3, Vitis vinifera, Stilbenes, Plasmopara viticola, avrRpv

\section{Background}

Plasmopara viticola, the causal agent of grapevine downy mildew, is one of the most economically important pathogens of grapevine. This host-specific oomycete pathogen is believed to have been introduced into Europe from North America in the late nineteenth century [1]. While North American and Asian Vitis species possess resistance loci against $P$. viticola, the cultivated European Vitis vinifera cultivars lack this genetic resistance, making them highly susceptible to this pathogen [1-3]. Consequently, viticulture is heavily dependent on the use of fungicides to prevention yield and quality losses, as demonstrated by the fact that more than $70 \%$ of the total quantity of fungicides used in Europe are applied in viticulture [4]. To reduce these ecological and economic burdens on wine production, several breeding programs have successfully introgressed resistance loci from wild North American and Asian Vitis species into V. vinifera resulting in new fungus-resistant grapevine cultivars (FRC) $[5,6]$. While numerous FRCs are available for wine production, distinct plant protection recommendations for these relatively new cultivars are missing. A total of 31 different quantitative trait loci (QTL) conferring resistance to downy mildew have been identified [7-9]. Despite the high number of resistance loci identified, most downy mildew-resistant cultivars grown in Europe rely on resistance conferred by the major dominant loci Rpv1 (Resistance to P. viticola 1), Rpv3, Rpv10 and Rpv12. A successful defense results in the occurrence of necrotic lesions, limited mycelial growth and a reduced number of sporangia in Rpv12-, Rpv10- and Rpv3-cultivars [2, 10-14]. The Rpv1- and Rpv3-loci originated from native North American grapevine species [12, 15], while Rpv10- and Rpv12-loci were introgressed from the Asian species Vitis amurensis [14, 16]. Resistance genes of the Rpv1- and Rpv3-loci encode specific receptor proteins with nucleotide-binding domains and leucine-richrepeats (NB-LRRs), allowing a specific recognition of $P$. viticola at the site of infection [17, 18]. Plants possess a basal immune system, which is based on the recognition of pathogen-associated molecular patterns (PAMPs) or endogenous molecules, which are referred to as damage- or danger-associated molecular patterns (DAMPs) by transmembrane pattern recognition receptors (PRRs) on the external surface of the host cell [19]. This recognition activates PAMP-triggered immunity (PTI), which hinders infection by non-adapted pathogens [20]. In contrast, adapted pathogens deliver effectors, which suppress PTI and enable the pathogen to colonize the host plant (virulent pathogen isolates). Effectors are recognized by specific resistance proteins with NB-LRRs, during an incompatible plant-pathogen interaction [21]. This recognition results in a resistance of the plant to the pathogen and a transcriptional activation of several defense genes (ETI; effector-triggered immunity; avirulent pathogen) $[20,22,23]$. Interestingly, whereas development of ETI has been linked to co-evolution of mildew strains with wild American grapevine species, the co-evolutionary history of Asian wild grapevine species and mildew pathogens is still not completely understood [24-26].

During ETI, signal transduction pathways like mitogen-activated protein (MAP) kinases and WRKY transcription factors are activated, which in turn results into a rapid influx of calcium ions, a burst of reactive oxygen species (ROS), transcription of pathogenesis-related (PR) proteins and biosynthesis of phytoalexins, which finally leads to a hypersensitive response (HR) [22, 27, 28]. Due to evolutionary host adaption of pathogens, cultivation of resistant plants, which rely on a single resistance locus are at risk of breakdown by new virulent isolates of pathogens that can escape detection by the resistance proteins $[29,30]$. The arise of $P$. viticola isolates, which are able to overcome resistance mediated by the Rpv3locus is a well-known phenomenon in Europe and was shown in multiple studies [14, 31-33]. To minimize this threat, current grapevine breeding strategies aim to combine several $R p v$-loci within the one genotype, resulting in new FRC with durable resistance $[3,6,34]$. The durability of resistance of these new grapevine cultivars is of particular importance in viticulture, since grapevines are permanent fruit crops growing for up to 30 years in vineyards [35]. In the recent years the first FRC with polygenic resistance against $P$. viticola have been registered [36-38]. However, detailed knowledge of the mechanisms underlying the resistance conferred by the loci used in these new breeding lines is lacking.

One class of bioactive secondary metabolites, the phytoalexins, are thought to play a crucial role in the defense against $P$. viticola $[32,39,40]$. The phytoalexin trans-resveratrol is the precursor for a number of more fungitoxic stilbenes, such as $\varepsilon$-viniferin and trans-pterostilbene $[41,42]$. Besides this, Chang and co-workers 
proposed that trans-resveratrol could also play a role as signaling molecule during HR [43]. Initial investigations into the mechanism of Rpv12-mediated resistance showed that trans-resveratrol accumulated within $12 \mathrm{~h}$ post inoculation (hpi) and a HR was observed between 24 to 48 hpi $[14,39]$. For Rpv10-mediated resistance an increase in trans-resveratrol synthesis was observed as early as $7 \mathrm{hpi}$ and higher levels at $48 \mathrm{hpi}$ in Rpv10/ Rpv3- cultivars [44]. Rpv3-mediated resistance has been shown to be associated with cell death after 32 hpi, an increased level of trans-resveratrol between 24 and $72 \mathrm{hpi}$ and the accumulation of fungitoxic stilbenes $[32,45,46]$.

In this study the resistance mechanisms mediated by the Rpv10-, Rpv3- and/or Rpv12-loci on downy mildew development, sporulation ability, onset of $\mathrm{PCD}$, production of hydrogen peroxide and trans-resveratrol levels were evaluated and compared. Furthermore, a new $P$. viticola isolate was described overcoming the polygenic $R p v 3 / R p v 12$-mediated resistance. On-farm experiments demonstrate that the deployment of new FRC containing an Rpv3- and/or Rpv12-loci can markedly reduce fungicide applications in the vineyard, but also indicate the risk of development of $P$. viticola isolates that are able to overcome plant resistance by omitting plant protection treatments.

\section{Results}

\section{Evaluation of downy mildew resistance conferred by different $R p v$-loci}

To compare the level of resistance conferred by different $R p v$-loci against $P$. viticola, susceptible grapevine cultivars i.e. 'Müller-Thurgau' and 'Riesling' and grapevine cultivars with different $R p v$-loci i.e. 'Cabernet Blanc' and 'Regent' (Rpv3), 'Merlot Khorus' and 'Fleurtai' (Rpv12), 'Soreli' and 'Sauvignac' (Rpv12/Rpv3) and 'Muscaris' $(R p v 10)$ were inoculated with the P. viticola $\left(a v r R p v^{+}\right.$ isolate). To investigate the possible influence of the background genotype on the resistance response, two different cultivars were analyzed that contained Rpv12-, $R p v 3$ - or Rpv12/Rpv3-loci. The production of sporangia was significantly higher on susceptible genotypes $\left(\sim 40,000\right.$ sporangia $\left.\mathrm{ml}^{-1}\right)$ than on resistant genotypes $\left(\sim 0-4000\right.$ sporangia $\left.\mathrm{ml}^{-1}\right)$ at 6 days post inoculation (dpi) (Fig.A; B). However, even though P. viticola sporulation was strongly reduced in all resistant cultivars, significant differences in the degree of resistance were observed with the Rpv3-cultivars showing sporulation levels of $\sim 2500-4000$ sporangia $\mathrm{ml}^{-1}$ compared to cultivars, containing Rpv10-, Rpv12- or Rpv12/Rpv3-loci showing sporulation levels of less than 1000 sporangia $\mathrm{ml}^{-1}$ (Fig. 1A; B).
Timing of cell death and impairment of mycelial growth is dependent on the type of resistance locus

For all histochemical analysis, leaf discs from susceptible and resistant genotypes were inoculated with $P$. viticola isolate $a v r R p v^{+}$. For aniline blue staining leaf discs were sampled at 24, 48, 72, 96 hpi to observe the development of $P$. viticola mycelium (Fig. 2A-D). Based on the observations the development of $P$. viticola was categorized as follows: category I - no development of $P$. viticola mycelium, category II - minor development, category III - moderate development and category IV - extensive development (Fig. 2A-D). At $24 \mathrm{hpi}$, no differences in either the ability of zoospores to attach to the stomata or germ tube development or the formation of primary hyphae were observed between the different genotypes (Fig. 2A-D). However, at $48 \mathrm{hpi}$, mycelial growth was impaired in Rpv12-, Rpv12/Rpv3- and Rpv10-genotypes, whereas in Rpv3- and susceptible genotypes the mycelial growth progressed (Fig. 2A-D). Between 48 to $96 \mathrm{hpi}$, no further mycelium growth was observed in Rpv12- and Rpv12/Rpv3-genotypes (Fig. 2A) and a small amount of mycelium development was observed for the Rpv10genotype (Fig. 2B). Of the resistant genotypes, the most mycelial development was observed in the Rpv3-genotypes (Fig. 2C), but this was still moderate compared to the susceptible genotypes, which were entirely colonized by mycelium at $96 \mathrm{hpi}$ (Fig. 2D).

The time point at which programmed cell death (PCD) was induced during infection was determined by sampling discs at $6,8,10,12,24,28$ and $32 \mathrm{hpi}$ and staining with trypan blue. Co-staining of zoospores allowed the identification of infected stomata. The first appearance of PCD was observed in leaf cells of the $R p v 12$ - and the Rpv12/Rpv3-genotypes at $8 \mathrm{hpi}$, followed by the Rpv10-genotype at $12 \mathrm{hpi}$ and the Rpv3genotypes significantly later at $28 \mathrm{hpi}$ (Fig. 3A). No PCD was observed at any time points in the infected susceptible cultivar or the mock inoculation (water) control (Additional file 1A). After 6 days, the infected susceptible cultivar shows cell death, which is presumably caused by nutrient deprivation of the pathogen and therefore does not represent a defense reaction (Additional file 1B). To quantify the differences in the area of PCD, trypan blue staining was analyzed at 6 days post inoculation (dpi) in Rpv12-, Rpv12/Rpv3-, Rpv10- and Rpv3-genotypes (Fig. 3B;C). The cell death areas were measured using the ROI (region of interest) manager of the Fiji software. Five images of different leaf discs were taken at 20x magnification. Each cell death area was outlined by hand and each ROI was calculated by the program. The mean value in $\mathrm{mm}^{2}$ is displayed. The average PCD area at $6 \mathrm{dpi}$ for Rpv12- and Rpv12/ $R p v 3$-genotypes was found to be $\sim 6-7 \mathrm{~mm}^{2}$, which was 


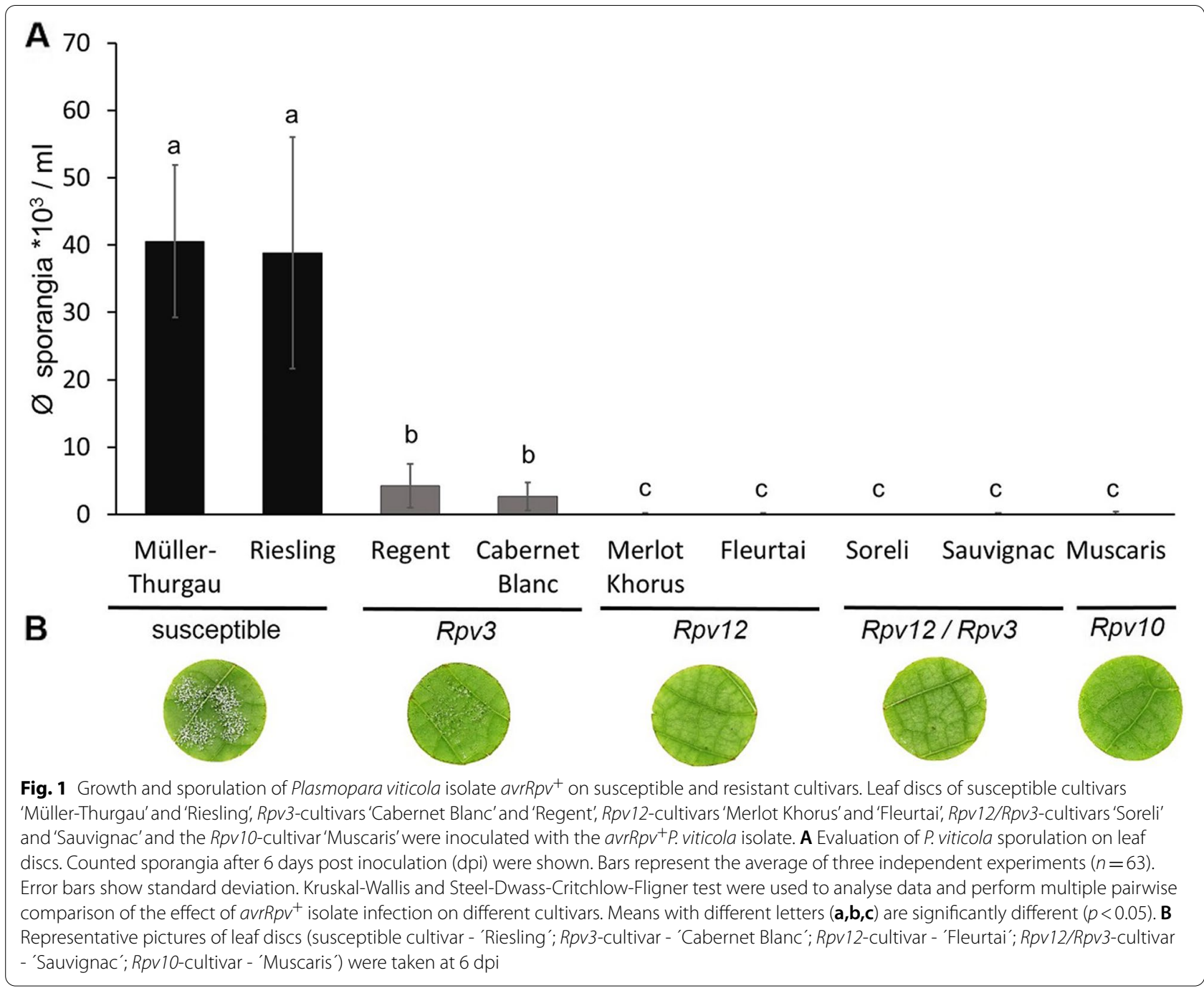

slightly lower, but not statistically significantly different to the Rpv10-genotype $\left(\sim 11.5 \mathrm{~mm}^{2}\right)$. However, the area of PCD observed in Rpv3-genotypes was significantly larger compared to the other resistant genotypes and was four times larger than that, observed in genotypes containing the Rpv12-locus.

As the Rpv12- and Rpv12/Rpv3-genotypes showed the earliest onset of PCD and the Rpv3-genotypes the latest onset, as well as the greatest difference in mycelium development (Fig. 2A-D), these genotypes were analyzed for the presence of an oxidative burst associated with PCD. Diaminobenzidine (DAB) staining confirmed hydrogen peroxide $\left(\mathrm{H}_{2} \mathrm{O}_{2}\right)$ production coincided with the induction of PCD at infection sites in all resistant genotypes. Hydrogen peroxide was detected in Rpv12and $R p v 12 / R p v 3$-genotypes at 8 hpi but not until 24 hpi in Rpv3-genotypes (Fig. 4A; B). No hydrogen peroxide formation was observed in the susceptible genotype
(Fig. 4A; B) or mock inoculation (water) controls (Additional file $2 \mathrm{~B}$ ).

\section{Trans-resveratrol production is more highly induced in response to $P$. viticola and precedes PCD}

A previous study proposed that trans-resveratrol may have a role as a signaling molecule for the induction of PCD, in addition to its known role as a phytoalexin [47]. We measured trans-resveratrol biosynthesis over $48 \mathrm{hpi}$ with $P$. viticola in susceptible and resistant genotypes in three independent experiments, except for the genotype 'Fleurtai', which was only analysed in two experiments. Figure 5 shows that trans-resveratrol levels in Rpv12genotypes were highly elevated in leaf discs 6 hpi with downy mildew in comparison to mock inoculated (water) leaf discs. In contrast, there was little or no induction of trans-resveratrol in the Rpv3- or susceptible genotypes. After 6 hpi the trans-resveratrol level in Rpv12-genotypes 


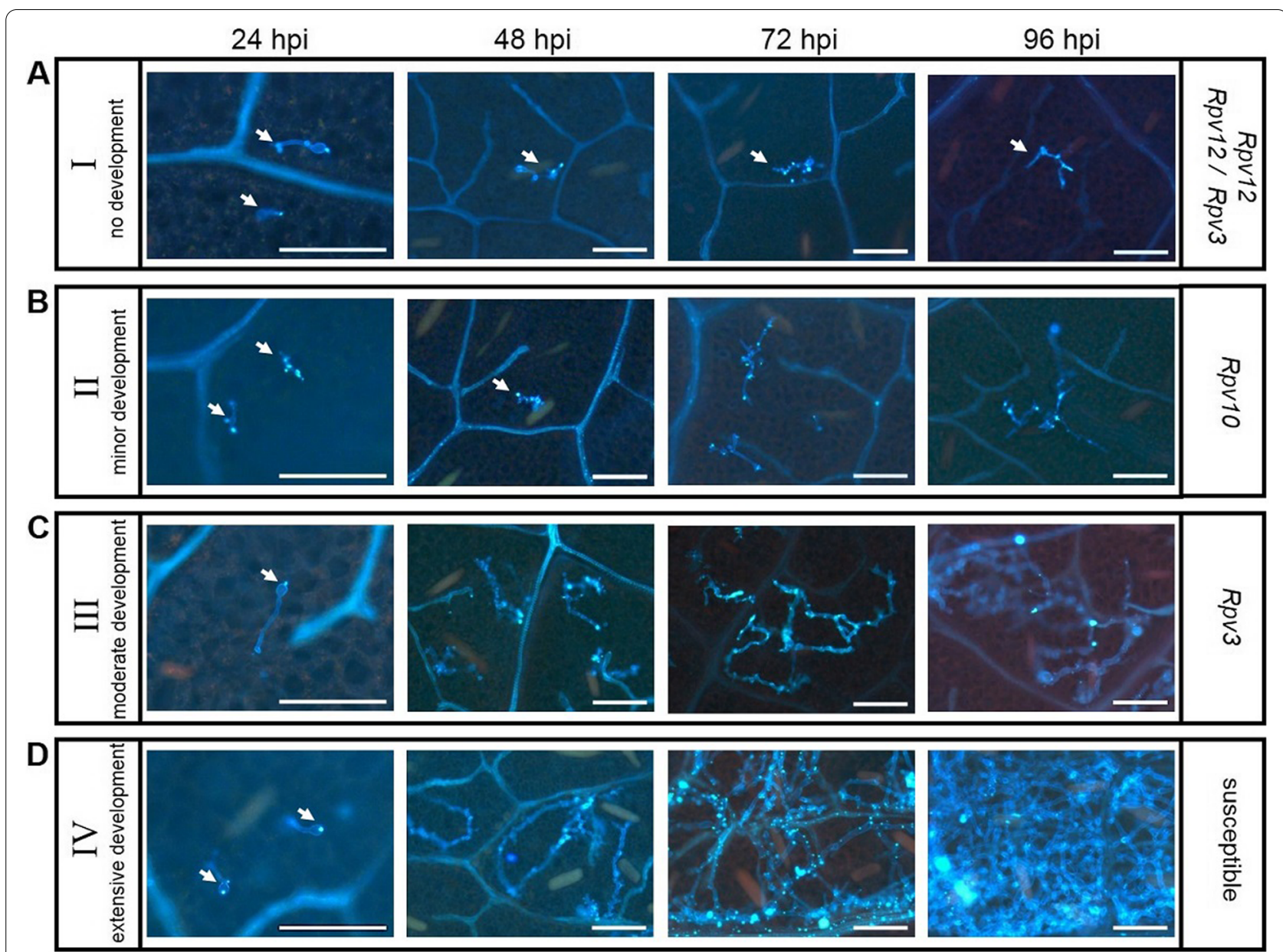

Fig. 2 Representative Plasmopara viticola development in leaves of susceptible and resistant cultivars. Mycelial growth of the P. viticola isolate $\left(\right.$ avrRpv $^{+}$) was evaluated using UV epifluorescence after aniline blue staining at 24 hours post inoculation (hpi), 48 hpi, 72 hpi, 96 hpi (left to right). Representative P. viticola development from cultivars within each category are shown: $\mathbf{A}$ category I - no development of $P$. viticola mycelium in Rpv12- and Rpv12/Rpv3-genotypes (pictures from 'Fleurtai'), B category II - minor development of P. viticola mycelium in Rpv10-genotypes (pictures from 'Muscaris'), C category III - moderate development of P. viticola mycelium in Rpv3-genotypes (pictures from 'Cabernet Blanc') and D category IV - extensive development of $P$. viticola mycelium in susceptible genotypes (pictures from 'Riesling'). Arrows highlight small P.viticola infection structures. Images are representative of three biological replicates and three independent experiments. Scale bars correspond to $100 \mu \mathrm{m}$

decreased such that there was no significant difference between any of the genotypes at 8 and 12 hpi. For the Rpv3-genotype an increase of trans-resveratrol was then observed from 12 to 24 hpi resulting in a significant higher level at $24 \mathrm{hpi}$ compared to the susceptible genotype.

\section{Rpv12/Rpv3 confers a higher degree of resistance in the vineyard than Rpv3-cultivar under strong infection pressure}

On-farm experiments were carried out in three commercial vineyards in Rhine-Palatinate region with varying in the number of fungicide treatments (Additional file 3), to evaluate the potential benefit of FRC in reducing the need for fungicide application. The recommended spray program for this region for susceptible cultivars is 9-11 treatments per season, depending on the infection pressure $[48,49]$. However, there is no information available as to the recommended fungicide spray program for FRCs. Therefore, we undertook experiments using three different fungicide treatment programs $(0,2$ or 4 applications per season) (Additional file 3), applied to the FRCs 'Sauvignac' (Rpv12/Rpv3) and 'Cabernet Blanc' (Rpv3). It was not possible to apply these reduced fungicide spray programs on susceptible cultivars, due to the high probability of complete crop loss for the grape growers. Therefore, the results of our reduced fungicide spray programs on $P$. viticola disease incidence and severity on the 


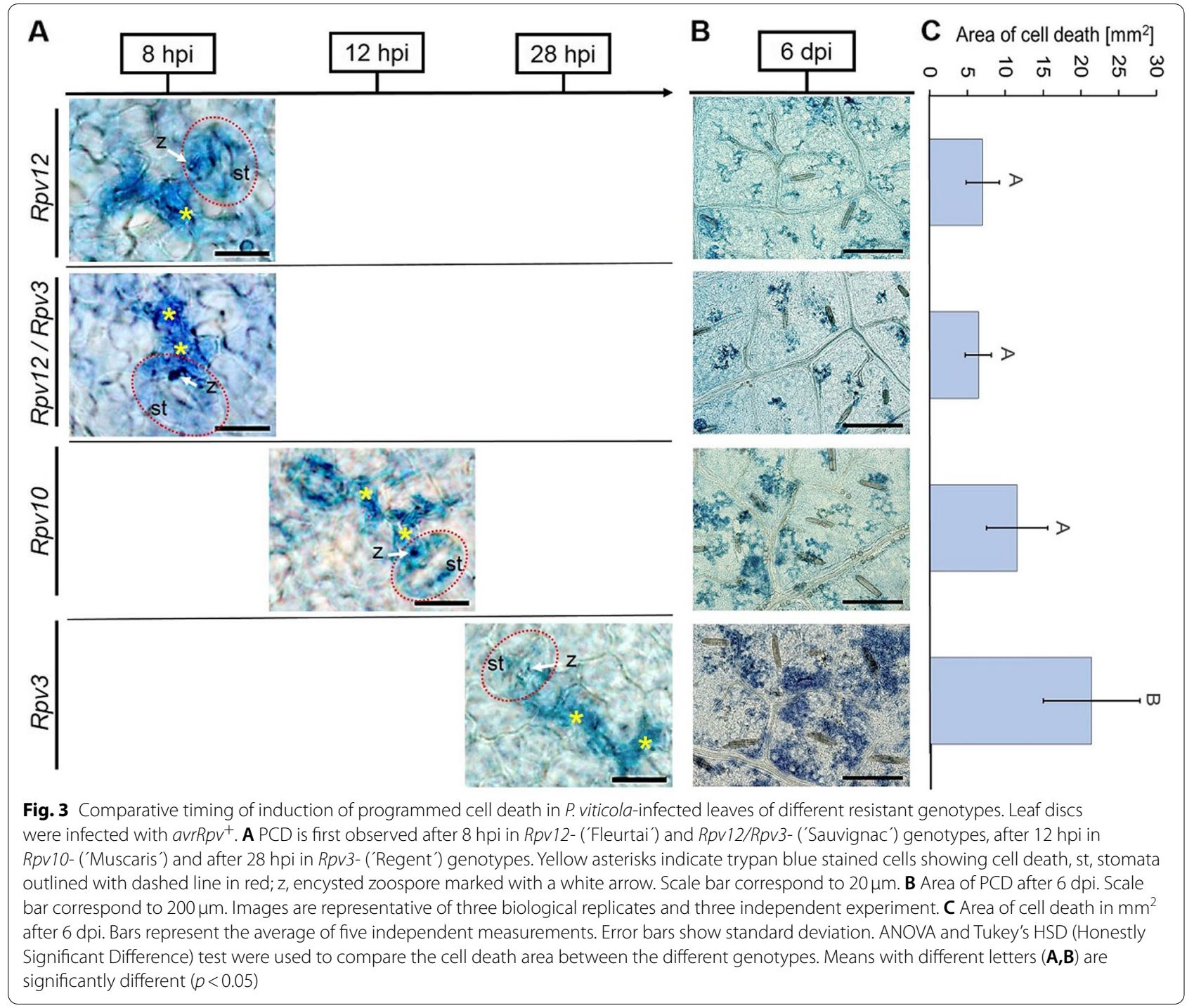

FRCs was compared with disease incidence and severity observed on the susceptible cultivar 'Kerner', which was treated as per normal commercial practices (2016: 6 applications until time of evaluation; 2017 and 2018: 9 applications) (Fig. 6). Plasmopara viticola disease incidence and severity on inflorescences, grapes and leaves were assessed weekly over three growing seasons.

No P. viticola infection was detected on 'Sauvignac' (Rpv12/Rpv3) over the 3 years of the trial for any of the spray variants in the three different vineyards, which translates to a fungicide saving of $100 \%$. In contrast, Rpv3-cultivar 'Cabernet Blanc' showed a higher susceptibility to P. viticola in 2016 and 2018 seasons (Fig. 6). During the 2016 season, disease incidence and severity on inflorescences on 'Cabernet Blanc' after three treatments were significant lower compared to 2 and 0 treatments in grapes (Fig. 6) and leaves (Additional file 4).
Despite the high disease incidence of $\sim 80 \%$ the disease severity of $\sim 14 \%$ was low enough to achieve yield and quality comparable to the susceptible cultivar 'Kerner', which showed similar disease incidence and severity levels, while treated 6 times at monitoring (Fig. 6). This represents a $50 \%$ reduction in fungicide applications for 'Cabernet Blanc' compared to 'Kerner' until BBCH 71 (Fig. 6). In 2016, P. viticola infection pressure was extremely high, therefore the study was stopped at $\mathrm{BBCH}$ 71 (start of fruit development) and fungicide application was performed as per normal commercial practices to ensure plant health.

In 2017 the weather conditions were not sufficient to trigger a primary infection or sporulation in the susceptible, $R p v 3-$ and $R p v 12 / R p v 3$-cultivars, resulting in $100 \%$ fungicide saving. Disease incidence and severity of $P$. viticola was lower in 2018, compared to 2016, but again 


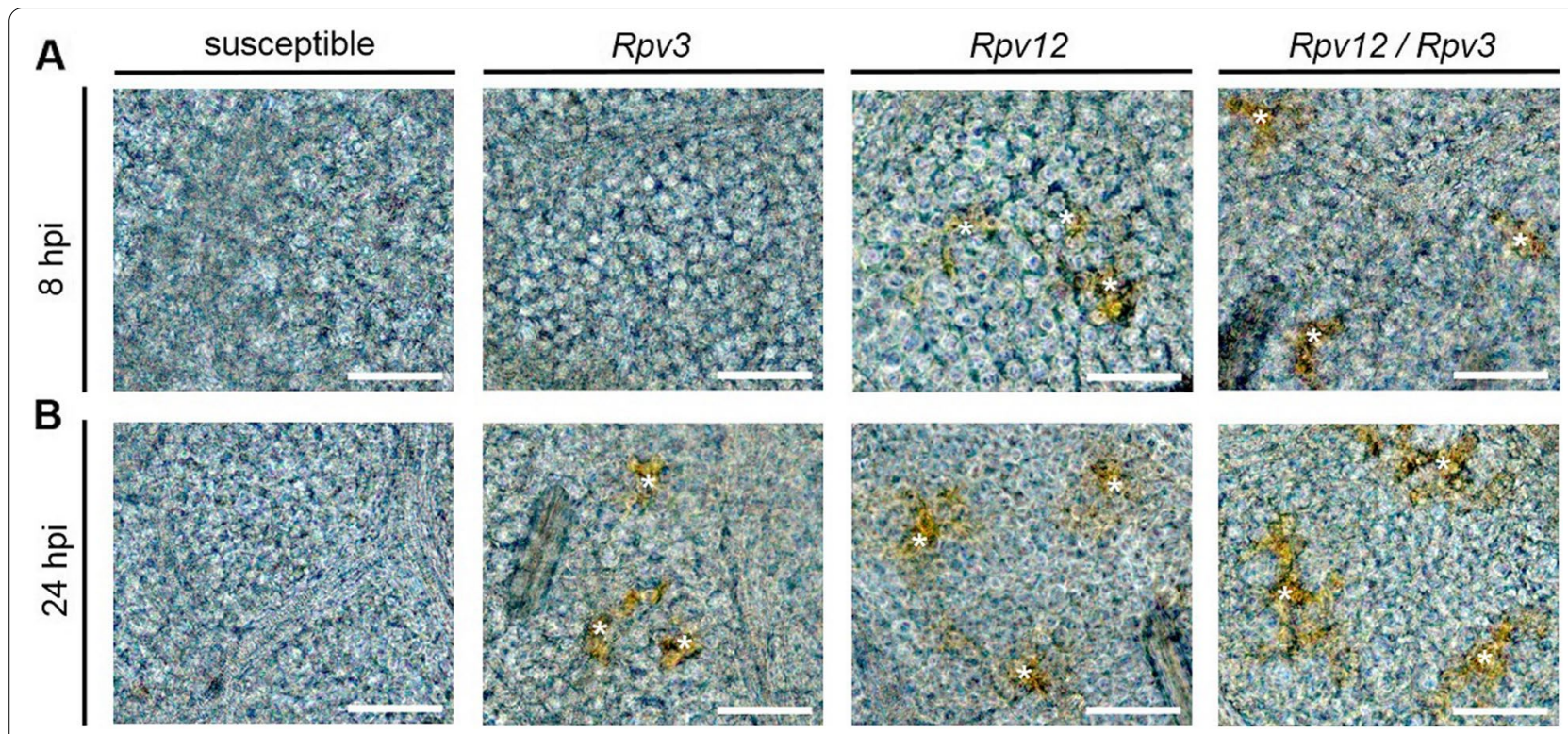

Fig. 4 Hydrogen peroxide production at Plasmopara viticola infection sites. P. viticola (avrRpv ${ }^{+}$) was used to inoculate leaf discs of susceptible genotype ('Müller-Thurgau') and resistant Rpv3- ('Regent'), Rpv12- ('Fleurtai') and Rpv12/Rpv3-genotype ('Sauvignac'). Samples were taken at 0, 2, 4, 6, 8, 10, 12, 24, 28, 32 and 36 hpi. Asterisks mark 3, 3'-diaminobenzidine-tetrahydrochloride stained cells indicating hydrogen peroxide formation. Images are representative of three biological replicates in three independent experiments $(n=9)$. Scale bars correspond to $50 \mu \mathrm{m}$

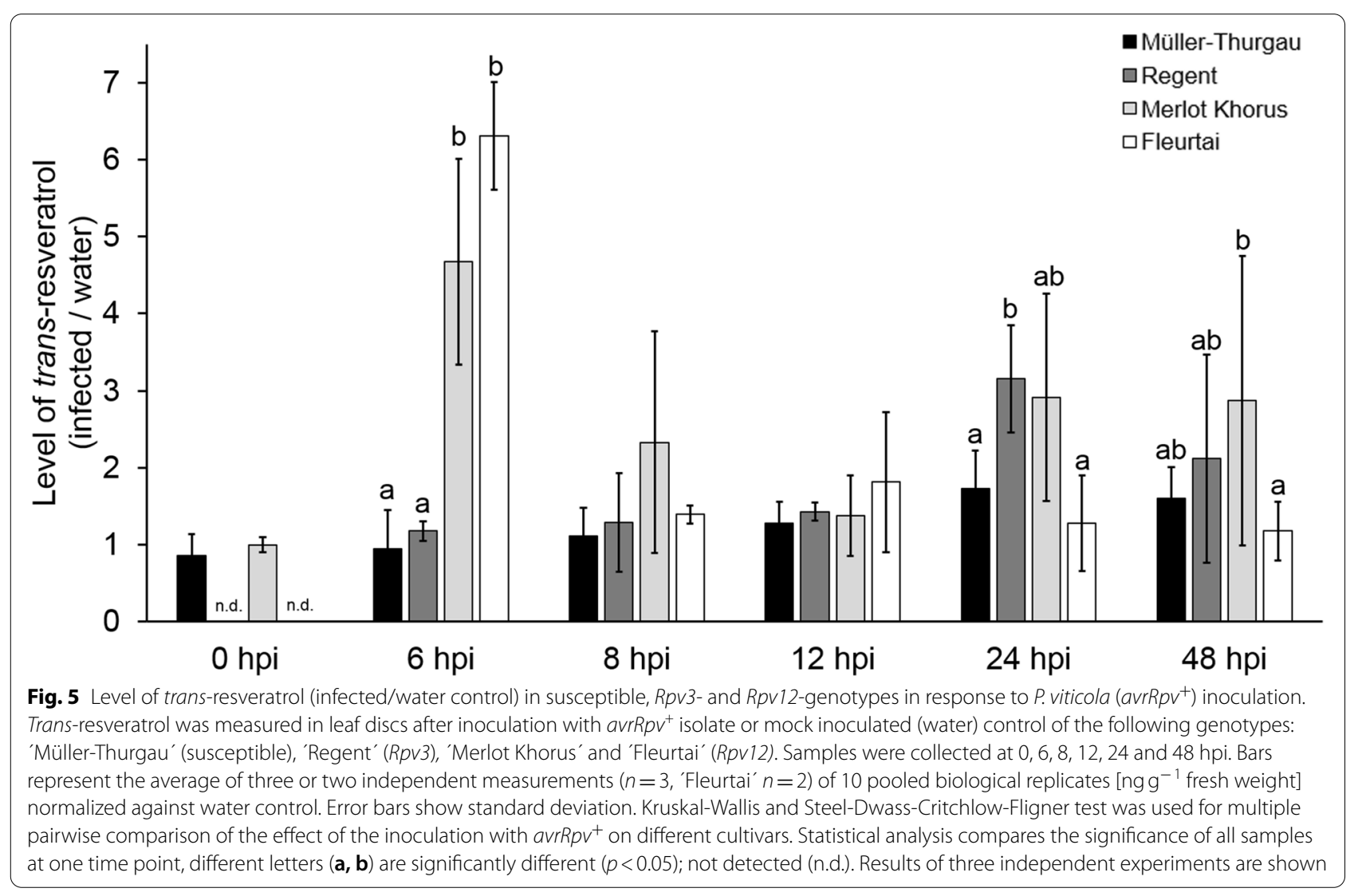




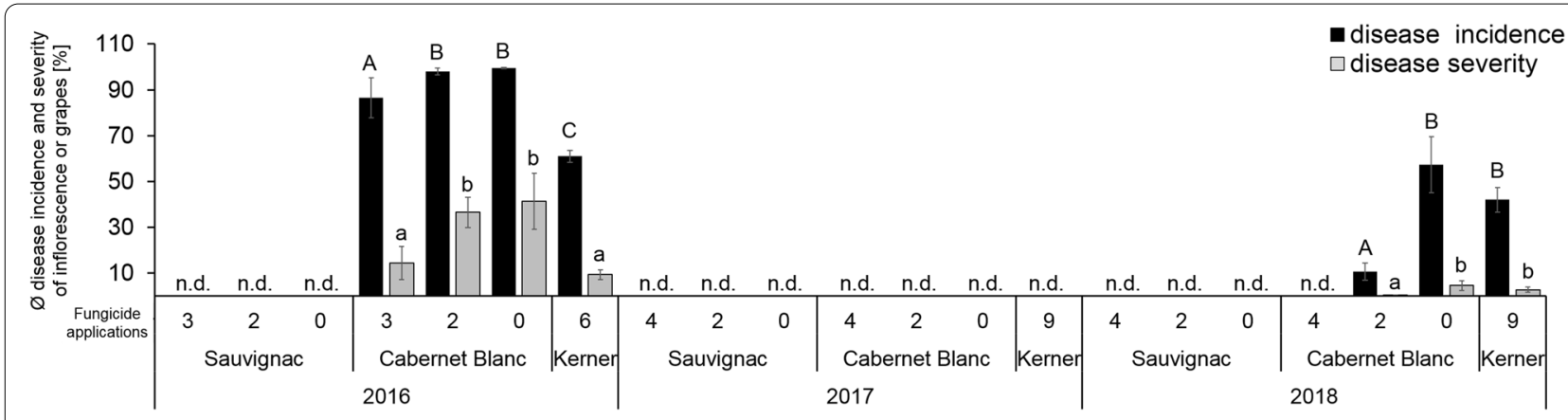

Fig. 6 Plasmopara viticola disease incidence and severity in inflorescences (BBCH 71 - 2016) and grapes (BBCH 75 and 88 - 2017, 2018). Disease incidence (black bars) and disease severity (grey bars) were quantified over three seasons in the grapevine cultivars 'Sauvignac' (Rpv12/Rpv3), 'Cabernet Blanc' (Rpv3) and 'Kerner' (susceptible), differing in the number of fungicide applications during the season. The bars show mean values for two different locations in 2016 ( $\mathrm{n}$ (grapes/application number) =200) and from three different locations in 2017 and 2018 (n (grapes/application number $=300$ ) for 'Sauvignac' and 'Cabernet Blanc'. Data from 'Kerner' are mean values of one location $n=100$. Error bars show standard error (SEM); no infections detected (n.d.). Kruskal-Wallis and Conover-Iman test was used to compare the disease incidence $(\mathbf{A}, \mathbf{B}, \mathbf{C})$ and severity $(\mathbf{a}, \mathbf{b}, \mathbf{c})$ for each year, $p<0.05$

showed that unsprayed grapevines displayed a significantly higher disease incidence and severity on 'Cabernet Blanc' grapes (Fig. 6) and leaves (Additional file 4). In 2018 the susceptible cultivar was treated 9 times resulting in comparable disease incidence and severity as found in the untreated 'Cabernet Blanc' grapes. Four fungicide applications gave complete control of $P$. viticola infection on 'Cabernet Blanc' grapes (55\% reduction of fungicide applications) and two treatments were sufficient to result in no yield and quality loss (75\% fungicide application reduction) (Fig. 6).

\section{Identification of a new Plasmopara viticola isolate that can overcome both Rpv12- and Rpv3-mediated resistance}

Mutations driven by selection processes are the main cause for adaptation of pathogens to their hosts. We previously reported on the identification of an $a v r R p v 3^{-}$isolate that is virulent on 'Cabernet Blanc' (Rpv3) from one of the vineyards in the Rhineland-Palatinate region that was used in this fungicide study [32]. More recently, we observed downy mildew growing on the cultivar 'Sauvignac' (Rpv12/Rpv3) in an isolated vineyard of Valentine Blattner (VB) in Soyhières, Switzerland (2019). This VB-isolate was collected and propagated and tested on a range of different grapevine genotypes. To evaluate whether the VB-isolate has resistance-breaking properties the amount of newly produced sporangia, mycelium development and induction of cell death were investigated by inoculating a range of susceptible and downy mildew-resistant cultivars containing different $R p v$-loci.

The level of sporulation of the avrRpv $3^{-}$isolate was significantly higher on all susceptible and Rpv3-1 cultivars $\sim 34,000-47,000$ sporangia $\left.\mathrm{ml}^{-1}\right)$ compared to Rpv12$\left(\sim 0-60\right.$ sporangia $\left.\mathrm{ml}^{-1}\right)$ and Rpv10-( 2600 sporangia $\mathrm{ml}^{-1}$ ) cultivars (Fig. 7A). However, no significant difference in sporulation was detected between Rpv12-, Rpv3-, Rpv12/Rpv3- and susceptible cultivars $(\sim 17,000-36,000$ sporangia $\mathrm{ml}^{-1}$ ) inoculated with the VB-isolate showing its ability to overcome $R p v 3$ - and $R p v 12$-mediated grapevine resistance ( $\left.a v r R p v 12^{-} / 3^{-}\right)$. However, the VB-isolate was not able to overcome $R p v 10$-mediated resistance, as the Rpv10-cultivar showed a significant and strongly reduced number of sporangia (less than 200 sporangia $\mathrm{ml}^{-1}$ ) (Fig. 7A). These results demonstrate for the first time the development of a $P$. viticola isolate, which is able to simultaneously overcome both the Rpv3- and Rpv12-loci.

To further investigate the effects of the resistance breaking isolates on pathogen development and PCD, aniline blue and trypan blue staining were performed. Once a pathogen overcomes resistance, mycelial development was comparable to that in susceptible cultivars and no cell death was observed. (Figs. 2 and 3, Additional files 5 and 6). The results confirm the resistance-breaking properties described in the sporulation assay (Fig. 7).

\section{Discussion}

Differences in the defense responses mediated by the Rpv3-, Rpv12- and Rpv10- loci in response to $P$. viticola infection

In plant-pathogen interactions with biotrophic pathogens, the initiation of PCD is associated with plant resistance and can be visible as macro or micro-necrotic lesions at the infection site [50]. Macroscopically visible lesions were reported in multiple resistant grapevine genotypes within 2-10 dpi but these studies reported no macroscopic difference in type and timing of the plant defense response in Rpv3- and Rpv12-locus containing 


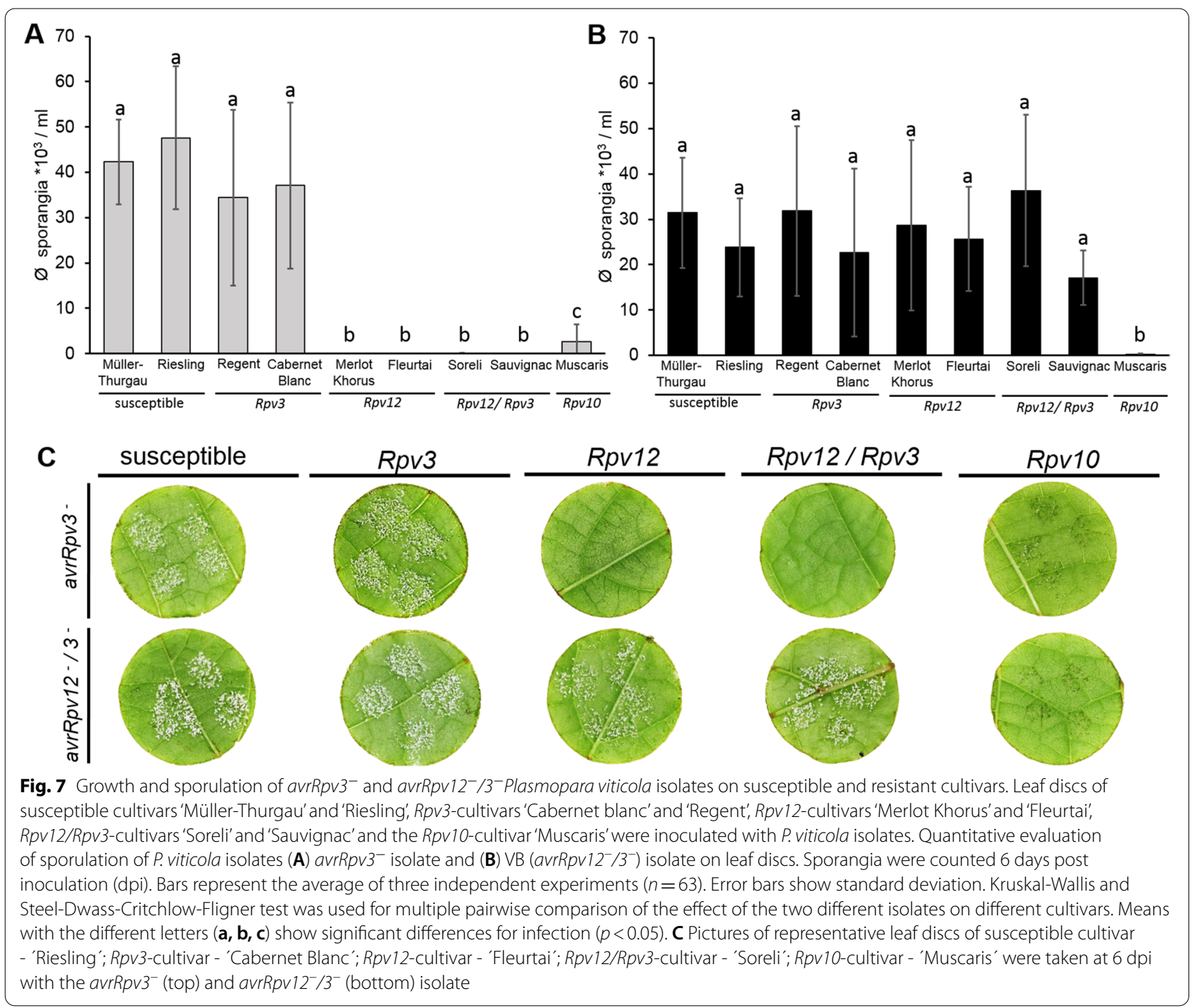

genotypes [12, 14, 44, 51]. In contrast, this study focused on the early response to $P$. viticola between 6 and $32 \mathrm{hpi}$ and investigated the different genotypes under the same experimental conditions and with the same P. viticola isolates. The comparison of the initiation and development of grapevine defense responses against $P$. viticola infection in resistant cultivars containing different downy mildew resistance loci revealed clear temporal differences in the onset of PCD in response to P. viticola in Rpv12, Rpv10- and Rpv3-genotypes (Fig. 3A). An early onset of PCD was observed in Rpv12- (8 hpi) and Rpv10-genotypes (12 hpi), but a much slower response was observed in Rpv3-genotypes (28 hpi) (Fig. 3A). The rapid induction of PCD within 8 hpi in Rpv12-genotypes (Fig. 3A), results in the early arrest of pathogen growth with no mycelial development visible (Fig. 2A). In comparison, Rpv10mediated PCD was induced approximately 4 hours later
(Fig. 3A), resulting in a small amount of mycelial development compared to the Rpv12-genotypes (Fig. 2B). In Rpv3-genotypes, PCD was not observed in our experiments until 28 hpi (Fig. 3A), allowing moderate development of the pathogen (Fig. 2C). These results confirm the observations reported by Eisenmann et al. [32], who found PCD was not induced in the Rpv-3 genotype at 32 hpi. These results are in good accordance with the theory that the timing of the defense initiation define the resistance level and successful plant defense [52-54].

The first interaction of $P$. viticola with the plant cell takes place after the development of the pathogen haustoria, which are the cell-wall-penetrating and feeding structures of $P$. viticola. They are established and invaginate the plasma membrane of the parenchyma cells between 3.5 and 6 hpi $[55,56]$. The fast and local PCD observed in Rpv12-genotypes at $8 \mathrm{hpi}$ and the complete 
growth inhibition of the pathogen stands in contrast to the late cell death in Rpv3-genotypes observed at $28 \mathrm{hpi}$ and the ongoing growth of the pathogen after first haustorium establishment. This early and late timing of PCD induction correlates with a differences in the area of PCD after 6 days post inoculation (Fig. 3A-C) presumably caused by the ongoing development of new haustoria for Rpv3-genotypes, resulting in trailing PCD. The late cell death observed in Rpv3-genotypes after $28 \mathrm{hpi}$ is presumably not caused due to nutrient deprivation by the pathogen, since cell death reaction was not observed in the susceptible cultivar at $32 \mathrm{hpi}$ (Additional file 1A). One can only speculate at this stage as to the reason(s) for the observed differences in timing of the induction of PCD mediated by the different $R p v$ loci. One possible factor may be differences in the timing of secretion of the $P$. viticola effectors that are recognized by the NBLRR resistance protein encoded by the Rpv locus or the expression of defense related genes. For example, Yin et al. [57], showed that the recognition of the effectors secreted during $P$. viticola infection show very different transcriptional profiles with some expressed highly within the first $12 \mathrm{hpi}$ and others not induced until $24 \mathrm{hpi}$ [57]. Other differences may also relate to recognition of the activated NB-LRR protein by the downstream signaling components.

\section{Role of reactive oxygen species and stilbenes in the defense response to downy mildew}

Effector-triggered immunity (ETI) is not only characterized by the induction of PCD but also a number of other cellular events including the rapid production of reactive oxygen species (ROS) and the release of antimicrobial compounds, such as phytoalexins, which are involved in successful limitation of pathogen development [22, 40, 58]. Furthermore, ROS like hydrogen peroxide have been proposed to act as signaling molecules for activation of defense genes and the HR $[59,60]$.

To obtain further insights into the observed timing differences mediated by different downy mildew resistance loci, the accumulation of hydrogen peroxide and the phytoalexin trans-resveratrol were compared in genotypes containing the Rpv12-locus with genotypes only containing Rpv3-locus. Our results demonstrate that hydrogen peroxide was produced within $8 \mathrm{hpi}$ at the infection site in Rpv12-genotypes which co-incided with the appearance of PCD (Fig. 4). In contrast, hydrogen peroxide was not detected in Rpv3-genotypes until 24 hpi (Fig. 4), which was shortly before PCD and was first observed in leaf cells of this genotype (Fig. 3).

Trans-resveratrol has also been proposed as signal molecule for PCD [43]. Chitarrini et al. [39] evaluated transresveratrol accumulation in $R p v 12$-genotypes but their first sampling point was at $12 \mathrm{hpi}$, which is well after the first appearance of PCD in Rpv12-genotypes. Our results show a significant increase of the level of trans-resveratrol at $6 \mathrm{hpi}$, which is prior to the observed production of ROS and the appearance of PCD at 8 hpi (Figs. 3 and 4A). As the accumulation of trans-resveratrol precedes the first occurrence of ROS and PCD in Rpv12-genotypes, it is tempting to speculate that trans-resveratrol, or another stilbene derived from trans-resveratrol, may act as an inducer of ROS production and PCD. Indeed, metabolomic and transcriptomic data suggests that the Rpv12mediated resistance relies on a rapid activation of a broad set of inducible responses that take place within $12 \mathrm{hpi}$ [39, 43]. Recently Eisenmann et al. [32] also described elevated trans-resveratrol and $\varepsilon$-viniferin levels during Rpv3-mediated defense response shortly before the onset of PCD at 32 hpi. Our results confirm that observation, with no significant increase of trans-resveratrol production in the Rpv3-genotype observed until 24 hpi (Fig. 5). Besides the possible role of trans-resveratrol as a signaling molecule, it has also been proposed to play a role in the Rpv3-mediated defense [32, 45], by acting as precursor for synthesis of the fungi-toxic stilbenes $\varepsilon$-viniferin and trans-pterostilbene, which suppress the growth and development of $P$. viticola [42].

Interestingly, Chitarrini et al. [39] found no evidence of an increase in $\varepsilon$-viniferin levels during Rpv12-mediated defense, leading them to conclude that the primary role of trans-resveratrol in the Rpv12-mediated resistance is as a signaling molecule in ROS formation and initiation of PCD rather than as a precursor of toxic stilbenes.

While the results presented here do not provide any further insights into the role of $R p v$-mediated stilbene production in suppressing $P$. viticola growth directly, they do provide support the hypothesis that trans-resveratrol may act as a signaling molecule for ROS induction and PCD in Rpv12- and Rpv3-mediated resistance. In the case of the Asian grapevine species and the respective resistance loci $R p v 10$ and $R p v 12$ it is not clear whether coevolution with mildew pathogens has taken place due to the lack of historical reports [24-26]. Therefore, it cannot be excluded that in contrast to a specific ETI found in American grapevines, another form of immunity (ETIlike immunity) plays a role in the defense reaction of Asian species [24].

\section{Relative resistance level mediated by the Rpv3-1-, Rpv10- and Rpv12-loci}

The resistance conferred by the Rpv3-, Rpv10- and Rpv12loci to $P$. viticola have been reported in a number of previous studies $[12,14,51,61-63]$. However, the results of these studies, in terms of the level of resistance mediated by the respective loci, are somewhat contradictory. 
For example, Possamai et al. [51] reported that the $R p v 10$-mediated resistance was weaker than that conferred by Rpv12 and Rpv3. Bove and Rossi [61], on the other hand, found comparable levels of downy mildew resistance in Rpv3-, Rpv10- and Rpv12-cultivars. The results of this current study demonstrate clear differences in the level of resistance conferred by the $R p v 3$ relative to $R p v 12$ or $R p v 10$. Sporulation on Rpv3-cultivars was significantly higher compared to $R p v 10-, R p v 12$-cultivars (Fig. 1). These findings are also in line with previous studies showing a higher resistance level of Rpv10- and $R p v 12$ - compared to Rpv3-mediated resistance (Fig. 1) $[14,63,64]$. One possible explanation for these conflicting results could be the different methods used to evaluate levels of resistance. In the present study, resistance was assessed using the measurement of sporulation on individual leaf discs whereas Possamai et al. [51] used a visual scoring system based on the Office International Organisation of Vine and Wine (OIV) [65] scale and Bove and Rossi [61] determined the amount of sporangia of specific lesions. In all studies, the time of the experiments was between April and August and should therefore not be considered as a determining factor for the different results. Another possible explanation for the observed differences in resistance levels between these different studies may be related to plant material sampled for each study. Possamai et al. [51] and Bove and Rossi [61] used leaf discs that were cut from field plants whereas Venuti et al. [14] and this study used leaf discs sampled from greenhouse plants.

\section{Emergence of a new field isolate that overcomes both Rpv12- and Rpv3-1-mediated resistance}

The emergence of resistance-breaking pathogens by mutations or deletions of avirulence genes and their selection by plant resistance genes have been previously described for several resistant crops such as potato and rice $[29,30,66,67]$. In addition, oomycetes are known to quickly overcome genetic resistance, as shown for sunflower downy mildew [68] and potato late blight [69]. Plasmopara viticola isolates that are able to overcome Rpv3-mediated resistance have been described in previous studies, demonstrating that the durability conferred by a single resistance locus may be limited [13, 31-33]. Our results show that an avrRpv3 ${ }^{-}$isolate has further mutated to also be able to overcome Rpv12-mediated resistance (Fig. 7). Therefore, a combination of several resistance loci is of great importance for grapevine breeding $[3,6,34,36]$. Despite this, our results demonstrate that $P$. viticola isolates overcoming two resistance loci can evolve.

A P. viticola isolate overcoming Rpv3- and Rpv12loci was detected in a vineyard in which inadequate phytosanitary treatments were performed over the last 3 decades. In this vineyard, an Rpv3-cultivar was first planted allowing the selection of an $R p v 3$-breaking isolate. Thereafter an Rpv12-cultivar was planted, resulting in the further development of this isolate (Fig. 7A; Additional file 5), designated as avrRpv12- $/ 3^{-}$. This shows that if cultivars with the individual resistance loci are grown at the same location with inadequate or no phytosanitary treatments, resistance based on the pyramidization of separate resistance loci can be overcome. These findings demonstrate that the mutated avirulence proteins (avrRpv3 and avrRpv12) of this isolate are not recognized by the corresponding resistance gene ( $R$-gene) product of the Rpv3- and Rpv12-loci [20]. In contrast, the resistance mediated by the $R p v 10$-locus was not overcome by the avrRpv12- $/ 3^{-}$isolate (Fig. 7). Our results clearly indicate that the $R p v 12-, R p v 10$ - and $R p v 3$-mediated resistances are based on three different $R$-gene products detecting different $A v r$ proteins of downy mildew. Pyramidization of all three $R p v$-loci within the same genotype could further increase the durability of new resistant grapevine cultivars.

\section{The potential of resistant grapevine cultivars to reduce the number of fungicide applications depends on the interplay of genetically based resistance levels, developmental and climatic factors}

Data from the Statistical Office of the European Union show that more than $70 \%$ of fungicides used in Europe are applied in viticulture [4]. This makes the issue of reducing fungicide applications more significant than for any other agricultural commodity. Fungus-resistant cultivars are one important component of achieving the goal of significantly reducing the use of plant protection products, to reduce the cost of production and the negative impacts of fungicides on the environment and the surrounding population. However, FRCs are currently grown on limited acreages, because of the low acceptance of new cultivars by wine growers and wine consumers. A survey among winegrowers in Germany highlighted the limited knowledge of adjusted plant protection recommendations for FRCs. This survey revealed that FRCs were either treated with the same number of fungicide treatments as susceptible cultivars or, conversely, plant protection was completely omitted [70]. Our study set out to evaluate the performance of FRCs fungicide application programs, which represented a $50-100 \%$ reduction in the number of applications required for acceptable disease control on existing susceptible cultivars in the same vineyard. The results showed the complete absence of $P$. viticola infections for the $R p v 12 / R p v 3$-cultivar across all treatments and experimental years (Fig. 6, Additional file 1). In contrast, downy mildew infections were observed on the 
Rpv3-cultivar in 2 out of 3 years with the reduced spray treatments (Fig. 6, Additional file 4). However, the level of downy mildew infection observed in those 2 years on the Rpv3-cultivar was similar to that observed with the susceptible control cultivar but with $50-100 \%$ fewer fungicide applications.

The performance of these $R p v$-loci in the vineyard, mirrors the results from laboratory-based leaf disc assays (Fig. 1) and highlights the fact that the identity of the resistance locus, present in a FRC has to be taken into consideration when designing the fungicide spray program that will maximize savings on fungicide application but still maintain yield and.

Furthermore, the results suggest that in addition to the genetically determined resistance levels, other factors such as climatic conditions during flowering and fruit set also play a role in the absolute resistance of a cultivar and thus, determine the amount of fungicide treatments required. The flower and fruit development phases are highly susceptible to pathogens [71]. Observations from Kennelly et al. [72] confirm our results observed at $\mathrm{BBCH}$ 71 in 2016, which indicated a positive correlation of an extended flowering period with a higher disease severity of inflorescences and berries. In contrast, 2018 the first P. viticola infection in the Rpv3-cultivar was detected after fruit set in $\mathrm{BBCH} 75$ and did not develop into a severe infection (Fig. 6). The result of the maximum saving found in this study with the Rpv3-genotype is in good agreement with described experiences of winegrowers and other [70, 73, 74]. However, these reports did not evaluate the saving potential during high infection periods, as in 2016, where reduction of fungicide applications by $\geq 75 \%$ cannot be compensated by $R p v 3$-cultivars without negative effects on yield or quality.

Our results demonstrate that the omission of plant protection can lead to significant amounts of infection, in some years, in FRCs that rely on Rpv3-mediated resistance alone. In two out of three experimental years the omission of plant protection treatments resulted in significantly higher infections with downy (Fig. 6; Additional file 4) and powdery mildew (data not shown). This is in contrast to the findings of Casanova-Gascón et al. [75], who observed no negative effects caused by the omission of plant protection for FRCs, possibly because of the lower infection pressure in their trails. Data over the three trial years showed that no downy mildew disease was observed on the Rpv12/Rpv3-cultivar even in the absence of any fungicide applications. However, in a long term the omission of plant protection applications is not a recommendation for practice, because as shown in this study, resistance-breaking isolates can develop if the levels of inoculum in the vineyard are allowed to increase. Taken together, this study highlights that the number of fungicide treatments required is not only defined by the genetically determined resistance levels, but also by other factors such as climatic conditions.

\section{Conclusion}

The experiments revealed an early and locally precise defense response in Rpv10-, Rpv12- and Rpv12/Rpv3-cultivars, whereas a delayed defense response in $R p v 3$-cultivars was observed. The differences in the timing of the defense response resulted in different resistance degrees of the various resistant grapevine cultivars, which were verified in lab experiments and on-farm experiments. The use of FRCs in combination with reduced plant protection management strategies offers the possibilities to significantly reduce the amount of fungicides required for grape production. Results obtained from the on-farm studies demonstrated that the deployment of FRCs may save $50-100 \%$ of fungicide applications in viticulture. However, the omission of all plant protection applications can ultimately lead to negative effects on yield, quality and even resistance durability. Future studies are needed to evaluate the consequences of reductions of fungicide applications on the emergence of other fungal diseases, such as black rot or Phomopsis viticola cane and leaf spot.

\section{Methods}

\section{Plant material, Plasmopara viticola isolates}

Vitis vinifera cv. 'Müller-Thurgau', 'Riesling'(susceptible), 'Regent' (Rpv3-1) [11, 34], 'Cabernet Blanc' (Rpv3-1) [32], 'Muscaris' (Rpv10) and 'Sauvignac' (Rpv12/ Rpv3) [38], were regenerated from canes obtained from vineyards of the State Education and Research Center of Viticulture, Horticulture and Rural Development, Neustadt/ Weinstr. Germany as described previously [76]. 'Merlot Khorus' (Rpv12) [37, 61] and 'Soreli'(Rpv12/Rpv3) [37] were regenerated from canes obtained from vineyards in Ungstein, Germany (vine nursery Krapp). Cuttings of 'Fleurtai' (Rpv12) [61] were provided from Viva Cooperativi Rauscedo (Italy) obtained from their vineyard. The plant material of this study has been identified and certified by Mr. Neser (Agricultural chamber of Palatinate, Neustadt, Germany) and is deposited in the herbarium of the Julius Kühn-Institut (Bundesforschungsinstitut für Kulturpflanzen, Geilweilerhof, Siebeldingen, Germany). Potted grapevines were grown under greenhouse conditions $\left(22^{\circ} \mathrm{C} /\right.$ day, $18^{\circ} \mathrm{C} /$ night; $50 \%$ humidity). The Plasmopara viticola isolates that are virulent on Rpv3-1 genotypes or avirulent on resistant genotypes were collected as described previously [32]. The $P$. viticola VBisolate, which overcomes Rpv12- and Rpv3-mediated resistance was isolated in Soyhières (Switzerland) in an isolated vineyard of Valentin Blattner (VB), in which an 
Rpv3-cultivar was cultivated over several years, followed by a $R p v 12$-cultivar. Inadequate plant protection treatments were performed in this vineyard. These isolates were designated $a v r R p v^{+}$(avirulent on all resistant cultivars), avrRpv3- (virulent on Rpv3-1-genotypes) and avrRvp12 $2^{-} / 3^{-}$(virulent on Rpv12- and/ or Rpv3-1-genotypes), followed the classification used by Casagrande et al. [13] and Eisenmann et al. [32]. Propagation of isolates was performed as described by Malacarne et al. [45].

\section{Leaf disc infection}

Leaf disc infection assay, with infection suspension containing 50,000 sporangia $\mathrm{ml}^{-1}$ or $\mathrm{dH}_{2} \mathrm{O}$ as control, was performed as described in Eisenmann et al. [32]. For sporulation experiments four $10 \mu \mathrm{l}$ droplets, for histochemical studies one $20 \mu \mathrm{l}$ and for HPLC experiments one $40 \mu \mathrm{l}$ droplet of zoospore suspension were placed on the abaxial leaf surface. Leaves were sampled from potted greenhouse grapes, which were grown from end of April until the beginning of June. The fourth and fifth leaf from the apex were used for sampling leaf discs. Experiments were performed in June to have optimum infection conditions.

\section{Phenotypic assessment of plant resistance to Plasmopara viticola isolates}

For the evaluation of each $P$. viticola isolate, a total of 21 leaf discs were cut from leaves sampled from three individual plant replicates ('Müller-Thurgau', 'Riesling', 'Regent', 'Cabernet Blanc', 'Merlot Khorus', 'Fleurtai', 'Sauvignac', 'Soreli' and 'Muscaris'). Leaf discs were infected and incubated as described in Eisenmann et al. [32]. The pathogen development was macroscopically scored at 6 days post inoculation (dpi) (Canon EOS800D with a Sigma $105 \mathrm{~mm}$ F2.8 EX DG MACRO OS objective). The number of sporangia produced per leaf disc at six dpi was quantified by counting and used to describe the degree of P. viticola infection [76]. Presented are the mean values of three independent experiments. Averages were used for Kruskal-Wallis and Steel-Dwass-Critchlow-Fligner test to analyse the data. The software used for statistical analysis was XLSTAT 2019.3.2, Add-On for Microsoft Excel ${ }^{\circledR}$.

\section{Histochemical studies}

For all histochemical studies, a total of three leaf discs from three individual plants in three independent experiments $(n=9)$ were inoculated, incubated as previously described [32]. To observe the development of $P$. viticola within leaves aniline blue staining was performed according to Hood and Shew [77]. Samples were collected at 24, 48, 72 and $96 \mathrm{hpi}$ and documented with an epifluorescence microscope (ZEISS Axio Scope.A1; Kübler
HXP-120C lighting device; camera: Axiocam MRc; filter set: Zeiss 05). Cell death was detected by trypan blue staining at 6, 8, 12, 24, 28 and 32 hpi as described by Koch and Slusarenko [78]. Stained leaf discs were analyzed with a ZEISS Axio Scope.A1 microscope with a Zeiss Axiocam MRc camera. Area of cell death was measured with the software Fiji [79]. The cell death areas were measured using the ROI (region of interest) manager of the Fiji software. Five images of different leaf discs were taken at 20x magnification. Each cell death area was outlined by hand and each ROI was calculated by the program. The mean value in $\mathrm{mm}^{2}$ is displayed. Error bars show the standard deviation. Diaminobenzidine staining was used to detect hydrogen peroxide formation in $P$. viticola infected leaf discs. The staining method was adapted from Daudi and O'Brien [80]. Infected leaf discs were sampled at 0, 2, 4, 6, $8,10,12,24,28$ and 32 hpi. Therefore, they were placed $1 \mathrm{~h}$ before sampling time point at a distance of $6.5 \mathrm{~cm}$ under a LED-lamp (PHILIPS GreenPower LED production module deep red/white $15050-60 \mathrm{~Hz}$ and $35 \mathrm{~W}$ ) with $\sim 672.5 \mu \mathrm{mol} \mathrm{s}^{-1} \mathrm{~m}^{-2}$ (measured with LI-250A light meter; sensor: LI-core Qantum) to open the stomata. The infection droplet was removed before staining them with diaminobenzidine staining solution (3, 3'-diaminobenzidin-tetrahydrochlorid $1 \mathrm{mg} \mathrm{ml}^{-1}$ in water, TWEEN 20 $\left(0.05 \%\right.$ (v/v)), $200 \mathrm{mM} \mathrm{Na}_{2} \mathrm{HPO}_{4}$, Break-Thru (0.1\% (v/v)). Each leaf disc was vacuum infiltrated twice $30-60 \mathrm{~s}$ followed by incubation for $30 \mathrm{~min}$ in the dark. Destaining (ethanol: acidic acid: glycerine (3:1:1)) was performed for 15-30 min in a boiling water bath. Microscopic analysis was performed with ZEISS Axio Scope.A1 microscope with a Zeiss Axiocam MRc camera. For all histochemical studies Zen blue software was used.

\section{Measuring of trans-resveratrol}

One experiment consists of 10 individual leaf discs from 5 individual plants ('Müller-Thurgau', 'Regent', 'Fleurtai' and 'Merlot Khorus'). Samples per treatment (infected/mock) were pooled together at $0,6,8,12,24$, 48 hpi $(n=10)$ and repeated three times $(n=3)$, except of 'Fleurtai' $(n=2)$. Prior to freezing in liquid nitrogen the outer $2 \mathrm{~mm}$ wounded edge of each leaf disc was removed to reduce potential effects of the wounding caused by cutting of the discs in stilbene production. The leaf discs were spread on a petri dish, infected and stored as described above. Stilbenes were extracted as described by Höll et al. [81]. The extracts were analyzed with HPLC (Jasco 4000er, Jasco AS-4150 autosampler, Jasco PU-4180 pump). Extracts were separated with a reversed phase column (Gemini-NX $3 \mu \mathrm{m}, \mathrm{C} 18110 \AA$, LC column $150 \times 4.6$ (Phenomenex ${ }^{\circledR}$ LTD, Aschaffenburg, Germany) protected by a pre-column. Trans-resveratrol levels were measured with a photo diode array detector (Jasco MD-4010) at 
$320 \mathrm{~nm}$ excitation wavelength. Separation was performed with a gradient of buffer A $\left(10 \mathrm{mmol} \mathrm{KH}_{2} \mathrm{PO}_{4} ; 5 \%(\mathrm{v} / \mathrm{v})\right.$ acetonitrile (HPLC grade); $95 \%(\mathrm{v} / \mathrm{v})$ water (HPLC grade); $\mathrm{pH}$ adjusted with $85 \% \mathrm{H}_{3} \mathrm{PO}_{4}$ to 1.5$)$ to buffer $\mathrm{B}(10 \mathrm{mmol}$ $\mathrm{KH}_{2} \mathrm{PO}_{4} ; 50 \%(\mathrm{v} / \mathrm{v})$ acetonitrile (HPLC grade); $50 \%(\mathrm{v} / \mathrm{v})$ water (HPLC grade); $\mathrm{pH}$ adjusted with $85 \% \mathrm{H}_{3} \mathrm{PO}_{4}$ to 1.5). The gradient conditions were $0 \mathrm{~min}, 90 \% \mathrm{~A} ; 7 \mathrm{~min}$, $66 \%$ A; $12 \mathrm{~min}, 49 \%$ A; $17 \mathrm{~min}, 68 \% \mathrm{~B} ; 22 \mathrm{~min}, 100 \% \mathrm{~B}$; 28 min, adjustment to initial conditions. The column was maintained at $25^{\circ} \mathrm{C}$ and the flow rate was $1 \mathrm{ml} \mathrm{min}^{-1}$. The emission detector was set to a wavelength range of 200-650 nm. Data acquisition and processing was performed with ChromNav Software (Jasco). For calculation of trans-resveratrol concentrations a calibration curve prepared from commercially available trans-resveratrol standard (Phyto-Lab) was used. The level of trans-resveratrol $\left(\mathrm{ngg}^{-1}\right.$ fresh weight (FW)) was normalized against untreated control. Results of three independent experiments are shown.

\section{Field trials}

Disease evaluation in the field was performed in a randomised block design of 25 grapevines per replicate with four replicates per treatment. For each rating block, 25 leaves and 25 grapes were evaluated randomly from both sides of the row. The location of rating blocks differed between all experimental years and was repositioned annually. Fungicide application trials using 'Sauvignac' and 'Cabernet Blanc' were undertaken at three commercial vineyards located in Rhineland-Palatinate, Germany. The fungicide treatment plan, as follows, was performed by the vineyard owners (Additional file 3). The time point of treatment was predefined to the grapevine development (BBCH-scale) according to Lorenz et al. [82], but the use of a specific fungicide was not requested. Identical treatment variants were chosen for both grape cultivars. In treatment variant four the first treatment took place during early leaf development (BBCH 15), followed by two treatments during flowering, (BBCH 57-60 \& BBCH 69) and a final treatment when berries reach pea-size (BBCH 75-77) (Additional file 3 ). The second variant was treated during flowering (BBCH 57-59 \& BBCH 69) and an untreated variant was monitored as a control to classify and compare annual natural infection pressure (Additional file 3). The susceptible cultivar 'Kerner' was treated conventionally, independent from the treatment plan, by the vineyard owner. In 2016 P. viticola infection pressure was extremely high, therefore the study was stopped by additional applications of a fungicide at $\mathrm{BBCH} 71$ to ensure plant health. The disease severity scheme of the European Plant Protection Organization (EPPO) was modified and used to assess disease severity [83]. Only seven symptom grades were used: $0 \%$, (no symptoms); $<5 \%$, $<10 \%,<25 \%,<50 \%,<75 \%$ and $\leq 100 \%$ infection. For the evaluation of disease incidence the same percentage scale was used. Average disease incidence and severity from different locations were used for statistical analysis. Due to extreme conditions or deficiencies in single locations, not all averages for all three locations during the various years of trials were compiled (2016: (n (grapes/ application number) $=200 ; 2017$ and 2018: (n (grapes/ application number) $=300$ ) and 'Kerner' 2016-2018: $n=100$. Kruskal-Wallis and Conover-Iman test were used to analyse the data. The software used for statistical analysis was XLSTAT 2019.3.2, Add-On for Microsoft Excel $^{\circledR}$.

\section{Abbreviations}

avrRpv $^{+}$: Avirulent on all resistant cultivars; avrRpv3": Virulent on Rpv3genotypes; avrRvp 12- $/ 3^{-}$: Virulent on Rpv12- and/ or Rpv3-genotypes; DAB: Diaminobenzidine; DAMPs: Danger-associated molecular patterns; dpi: Days post inoculation; ETI: Effector-triggered immunity; FRC: Fungus-resistant grapevine cultivars; $\mathrm{H}_{2} \mathrm{O}_{2}$ : Hydrogen peroxide; HR: Hypersensitive response; hpi: Hours post inoculation; NB-LRR: Nucleotide-binding domains and leucinerich-repeats; PAMPs: Pathogen associated molecular pattern; PRRs: Pattern recognition receptors; PTI: PAMP-triggered immunity; QTL: Quantitative trait loci; ROS: Reactive oxygen species; Rpv: Resistance to Plasmopara viticola.

\section{Supplementary Information}

The online version contains supplementary material available at https://doi. org/10.1186/s12870-021-03228-7.

Additional file 1. Trypan blue staining of susceptible cultivar upon $P$. viticola $\left(a v r R p v^{+}\right)$infection and mock inoculation (water). (A) Trypan blue staining of susceptible genotype ('Müller-Thurgau') upon infection with avrRpv ${ }^{+}$after 8, 12 and 32 hpi, st, stomata; $z$, encysted zoospore (scale bar correspond to $20 \mu \mathrm{m}$ ). (B) Trypan blue staining of susceptible genotype ('Müller-Thurgau') after mock inoculation and upon infection with avrRpv ${ }^{+}$ after $6 \mathrm{dpi}$ (scale bar correspond to $100 \mu \mathrm{m})$.

Additional file 2. Trypan blue and diaminobenzidine staining analysis of all genotypes upon mock inoculation (water). (A) Trypan blue staining of susceptible genotype ('Müller-Thurgau') and resistant Rpv3- ('Regent'), Rpv12- ('Fleurtai'), Rpv12/Rpv3- ('Sauvignac') and Rpv10-genotype ('Muscaris') after mock inoculation at $32 \mathrm{hpi}$ (scale bar correspond to $20 \mu \mathrm{m}$ ), st, stomata. (B) Diaminobenzidine staining of susceptible genotype ('Müller-Thurgau') and resistant Rpv3- ('Regent'), Rpv12- ('Fleurtai') Rpv12/ Rpv3-genotype ('Sauvignac') after mock inoculation at $24 \mathrm{hpi}$ (scale bar correspond to $50 \mu \mathrm{m})$.

Additional file 3. Plant protection treatment plan. Fungicide treatments were implemented according to the grapevine developmental stage $(B B C H)$. The different variants with four, two or zero treatments were evaluated during growing seasons. (+) Fungicide treatment at the appropriate $\mathrm{BBCH}$ stage was applied. (-) Absence of fungicide application.

Additional file 4. Plasmopara viticola disease incidence and severity in leaves (BBCH 71 - 2016; BBCH 75 - 2017, 2018). Disease incidence (black bars) and disease severity (grey bars) were quantified over three seasons in the grapevine cultivars 'Sauvignac' (Rpv12/Rpv3) and 'Cabernet Blanc' (Rpv3), differing in the number of fungicide applications during the season. The bars show mean values for two different locations in 2016 (n (grapes/application number) $=200$ ) and from three different locations in 2017 and 2018 (n (grapes/application number) =300). Error bars show standard error (SEM); no infections detected (n.d.). Kruskal-Wallis and Conover-Iman test was used to compare the disease incidence (A, B, C) and severity $(a, b, c)$ for each year, $p<0.05$. 
Additional file 5. Comparison of Plasmopara viticola development in leaves of susceptible and resistant cultivars. Development of (A) avrRpv12- $/ 3^{-}$and (B) avrRpv3 ${ }^{-}$P. viticola isolates on leaf discs of the susceptible genotype ('Müller-Thurgau') and resistant Rpv3- ('Regent'), Rpv12('Fleurtai'), Rpv12/Rpv3- ('Sauvignac') and Rpv10-genotype ('Muscaris'), were evaluated using UV epifluorescence after aniline blue staining at 96 hpi. Arrows indicate infection structures of $P$. viticola. Images are representative of three biological replicates in three independent experiments. Scale bars correspond to $100 \mu \mathrm{m}$.

Additional file 6. Induction of cell death at Plasmopara viticola infection sites. (A) avrRpv12- $/ 3^{-}$and (B) avrRpv3 $3^{-}$. viticola were used to inoculate leaf discs of susceptible genotype ('Müller-Thurgau') and resistant Rpv3('Regent'), Rpv12- ('Fleurtai'), Rpv12/Rpv3- ('Sauvignac') and Rpv10genotype ('Muscaris'), samples were taken at 8 hpi and 12 hpi. Yellow asterisks indicate trypan blue stained cells showing cell death, st, stomata; z, encysted zoospore. Images are representative of three biological replicates in three independent experiments. Scale bars correspond to $20 \mu \mathrm{m}$.

\section{Acknowledgements}

We would like to thank Valentin Blattner for the provision of the avrRpv12-/3isolate, Rauschedo for the cuttings of 'Fleurtai', Andreas Wirth (Rebschule Krapp) for the cuttings of 'Merlot Khorus' and 'Soreli' and the wineries: Weingut Anselmann; Edesheim, Weingut Nett; Geinsheim, Weingut Rummel; Landau-Nusdorf and Rebschule Freytag; Neustadt an der Weinstraße. Furthermore we would like to thank Merle Gabor, Tobias Ziegler, Jutta Kramm, Maja Kube, Manuel Baumann and Daniel Zimmermann for experimental assistance and Andreas Kortekamp for helpful advices.

\section{Authors' contributions}

CW contributed to project concept, conceptualized the experiments, conducted the laboratory experiments, analyzed the data and drafted the manuscript. BE conceptualized the project concept and experiments, carried out, analyzed and drafted the manuscript for the field trials and revised the manuscript. PW conducted the laboratory experiments, analyzed the data and drafted the manuscript. ID for manuscript revision. JB conceptualized the project concept and experiments, coordinated the project, and revised the manuscript. All authors read and approved the final manuscript.

\section{Funding}

Work of CW was funded by Deutsche Landwirtschafts-Gesellschaft (DLG) über den Forschungsring des Deutschen Weinbaus (FDW). Work of BE was partially funded by the European Union-European Regional Development Fund (ERDF) (A23 partial) as part of the program INTERREG IV Upper Rhine ("Transcending borders with every project"). The authors declare that the funding bodies had no role in the design of the study, in the collection, analysis, and interpretation of data or in writing the manuscript.

\section{Availability of data and materials}

The datasets supporting the conclusions of this article are included within the article and its additional files.

\section{Declarations}

\section{Ethics approval and consent to participate}

Not applicable.

\section{Consent for publication}

Not applicable.

\section{Competing interests}

The authors declare that they have no competing interests.

\section{Author details}

${ }^{1}$ State Education and Research Center of Viticulture, Horticulture and Rural Development, Neustadt/Weinstr, Germany. ${ }^{2}$ Centre for Organismal Studies Heidelberg, University of Heidelberg, Heidelberg, Germany. ${ }^{3} \mathrm{CSIRO}$ Agriculture \& Food, Urrbrae, SA 5064, Australia. ${ }^{4}$ Technische Hochschule Bingen, 55411 Bingen am Rhein, Germany.
Received: 27 April 2021 Accepted: 23 September 2021

Published online: 14 October 2021

\section{References}

1. Gessler C, Pertot I, Perazzolli M. Plasmopara viticola: a review of knowledge on downy mildew of grapevine and effective disease management. Phytopathol Mediterr. 2011;50:3-44

2. Di Gaspero G, Copetti D, Coleman C, Castellarin SD, Eibach R, Kozma P, et al. Selective sweep at the Rpv3 locus during grapevine breeding for downy mildew resistance. Theor Appl Genet. 2012;124:277-86.

3. Töpfer R, Hausmann L, Harst M, Maul E, Zyprian E, Eibach R. New horizons for grapevine breeding. Glob Sci Books. 2011;5:79-100 www.vivc.de.

4. Muthmann R, Nadin P. The use of plant protection products in the European Union; 2007. https://doi.org/10.2118/159520-MS.

5. Eibach R, Zyprian E, Töpfer R. The use of molecular markers for pyramidizing resistance genes in grapevine breeding. Vitis J Grapevine Res. 2007:46:120-4.

6. Merdinoglu D, Schneider C, Prado E, Wiedemann-Merdinoglu S, Mestre P. Breeding for durable resistance to downy and powdery mildew in grapevine. Oeno One. 2018:52:203-9.

7. Sargolzaei M, Maddalena G, Bitsadze N, Maghradze D, Bianco PA, Failla O, et al. Rpv29, Rpv30 and Rpv31: three novel genomic loci associated with resistance to Plasmopara viticola in Vitis vinifera. Front Plant Sci. 2020;11:1-16.

8. Dry I, Riaz S, Fuchs M, Sosnowski M, Thomas M. Scion breeding for resistance to biotic stresses. In: Cantu D, Walker MA, editors. The grape genome, vol. 2019. Cham: Springer Nature Switzerland AG; 2019. p. $319-47$.

9. Bhattarai G, Fennell A, Londo JP, Coleman C, Kovacs LG. A novel grape downy mildew resistance locus from Vitis rupestris. Am J Enol Vitic. 2021;72:12-20.

10. Gindro K, Pezet R, Viret O. Histological study of the responses of two Vitis vinifera cultivars (resistant and susceptible) to Plasmopara viticola infections. Plant Physiol Biochem. 2003;41:846-53.

11. Fischer BM, Salakhutdinov I, Akkurt M, Eibach R, Edwards KJ, Töpfer R, et al. Quantitative trait locus analysis of fungal disease resistance factors on a molecular map of grapevine. Theor Appl Genet. 2004;108:501-15.

12. Bellin D, Peressotti E, Merdinoglu D, Wiedemann-Merdinoglu S, AdamBlondon AF, Cipriani $\mathrm{G}$, et al. Resistance to Plasmopara viticola in grapevine "Bianca" is controlled by a major dominant gene causing localised necrosis at the infection site. Theor Appl Genet. 2009;120:163-76.

13. Casagrande K, Falginella L, Castellarin SD, Testolin R, Di Gaspero G Defence responses in Rpv3-dependent resistance to grapevine downy mildew. Planta. 2011:234:1097-109.

14. Venuti S, Copetti D, Foria S, Falginella L, Hoffmann S, Bellin D, et al. Historical introgression of the downy mildew resistance gene Rpv12 from the Asian species into grapevine Vitis amurensis varieties. PLoS One. 2013;8:1-7.

15. Merdinoglu D, Wiedeman-Merdinoglu S, Coste P, Dumas V, Haetty S, Butterlin $\mathrm{G}$, et al. Genetic analysis of downy mildew resistance derived from Muscadinia rotundifolia. In: Acta Horticulturae; 2003. p. 451-6.

16. Schwander F, Eibach R, Fechter I, Hausmann L, Zyprian E, Töpfer R. Rpv10: a new locus from the Asian Vitis gene pool for pyramiding downy mildew resistance loci in grapevine. Theor Appl Genet. 2012;124:163-76.

17. Foria S, Copetti D, Eisenmann B, Magris G, Vidotto M, Scalabrin S, et al. Gene duplication and transposition of mobile elements drive evolution of the Rpv3 resistance locus in grapevine. Plant J. 2020;101:529-42.

18. Feechan A, Anderson C, Torregrosa L, Jermakow A, Mestre P, WiedemannMerdinoglu S, et al. Genetic dissection of a TIR-NB-LRR locus from the wild north American grapevine species Muscadinia rotundifolia identifies paralogous genes conferring resistance to major fungal and oomycete pathogens in cultivated grapevine. Plant J. 2013;76:661-74.

19. Boller T, Felix G. A renaissance of elicitors: perception of microbe-associated molecular patterns and danger signals by pattern-recognition receptors. Annu Rev Plant Biol. 2009;60:379-406.

20. Jones JDG, Dangl JL. The plant immune system. Nature. 2006;444:323-9.

21. Dangl JL, Jones JDG. Defence responses to infection. Nature. 2001:411:826-33. 
22. Dodds PN, Rathjen JP. Plant immunity: towards an integrated view of plant-pathogen interactions. Nat Rev Genet. 2010;11:539-48.

23. Flor HH. Current status of the gene-for-gene concept. Annu Rev Phytopathol. 1971;9:275-96.

24. Jiao Y, Xu W, Duan D, Wang Y, Nick P. A stilbene synthase allele from a Chinese wild grapevine confers resistance to powdery mildew by recruiting salicylic acid signalling for efficient defence. J Exp Bot. 2016;67:5841-56.

25. Riaz S, Boursiquot JM, Dangl GS, Lacombe T, Laucou V, Tenscher AC, et al. Identification of mildew resistance in wild and cultivated central Asian grape germplasm. BMC Plant Biol. 2013;13.

26. Qiu W, Feechan A, Dry I. Current understanding of grapevine defense mechanisms against the biotrophic fungus (Erysiphe necator), the causal agent of powdery mildew disease. Hortic Res. 2015;2:1-9.

27. Meng X, Zhang S. MAPK cascades in plant disease resistance signaling Annu Rev Phytopathol. 2013;51:245-66.

28. McDowell JM, Dangl JL. Signal transduction in the plant immune response. Trends Biochem Sci. 2000;25:79-82.

29. McDonald BA, Linde C. Pathogen population genetics, evolutionary potential, and durable resistance. Annu Rev Phytopathol. 2002;40:349-79.

30. Pink DAC, Hand P. Plant resistance and strategies for breeding resistant varieties. Plant Prot Sci. 2002;38:9-13.

31. Delmotte F, Mestre P, Schneider C, Kassemeyer HH, Kozma P, Richart-Cervera $\mathrm{S}$, et al. Rapid and multiregional adaptation to host partial resistance in a plant pathogenic oomycete: evidence from European populations of Plasmopara viticola, the causal agent of grapevine downy mildew. Infect Genet Evol. 2014;27:500-8.

32. Eisenmann B, Czemmel S, Ziegler T, Buchholz G, Kortekamp A, Trapp O, et al. Rpv3-1 mediated resistance to grapevine downy mildew is associated with specific host transcriptional responses and the accumulation of stilbenes. BMC Plant Biol. 2019;19:1-17.

33. Peressotti E, Wiedemann-Merdinoglu S, Delmotte F, Bellin D, Di Gaspero $G$, Testolin $R$, et al. Breakdown of resistance to grapevine downy mildew upon limited deployment of a resistant variety. BMC Plant Biol. 2010;10:1-11.

34. Welter LJ, Göktürk-Baydar N, Akkurt M, Maul E, Eibach R, Töpfer R, et al. Genetic mapping and localization of quantitative trait loci affecting fungal disease resistance and leaf morphology in grapevine (Vitis vinifera L). Mol Breed. 2007;20:359-74.

35. Töpfer RE. Breeding for disease resistant varieties. In: The 16th Australian wine industry technical conference. Adelaide: Wine Industry Technical Conference Inc.; 2017. p. 74-6. https://awitc.com.au/proceedings/16AWI TC.pdf.

36. Schneider C, Onimus C, Prado E, Dumas V, Wiedemann-Merdinoglu S, Dorne MA, et al. INRA-ResDur: the French grapevine breeding programme for durable resistance to downy and powdery mildew. Acta Hortic. 2019;1248:207-13.

37. Colautti M, de Luca E, Khafizova A, Sartori E, Zambon Y, Ermacora P, et al. Phytosanitary defense of the disease-resistant grape varieties. Rauscedo, 2020. http://passthrough.fw-notify.net/download/511217/http://www. vivairauscedo.com/pdf/quaderni/Quaderno19-En.pdf.

38. Maul E. Vitis international variety catalogue. https://www.vivc.de/.

39. Chitarrini G, Riccadonna S, Zulini L, Vecchione A, Stefanini M, Larger S, et al. Two-omics data revealed commonalities and differences between Rpv12- and Rpv3-mediated resistance in grapevine. Sci Rep. 2020;10:1-15. https://doi.org/10.1038/s41598-020-69051-6.

40. Greenberg JT. Programmed cell death in plant-pathogen interactions. Annu Rev Plant Physiol. 1997:48:525-45.

41. Chong J, Poutaraud A, Hugueney P. Metabolism and roles of stilbenes in plants. Plant Sci. 2009;177:143-55.

42. Pezet $\mathrm{R}$, Gindro $\mathrm{K}$, Viret $\mathrm{O}$, Richter $\mathrm{H}$. Effects of resveratrol, viniferins and pterostilbene on Plasmopara viticola zoospore mobility and disease development. Vitis J Grapevine Res. 2004:43:145-8.

43. Chang X, Heene E, Qiao F, Nick P. The phytoalexin resveratrol regulates the initiation of hypersensitive cell death in Vitis cell. PLoS One. 2011;6:1-12.

44. Pezet R, Gindro K, Viret O, Spring JL. Glycosylation and oxidative dimerization of resveratrol are respectively associated to sensitivity and resistance of grapevine cultivars to downy mildew. Physiol Mol Plant Pathol. 2004;65:297-303.

45. Malacarne G, Vrhovsek U, Zulini L, Cestaro A, Stefanini M, Mattivi F, et al. Resistance to Plasmopara viticola in a grapevine segregating population is associated with stilbenoid accumulation and with specific host transcriptional responses. BMC Plant Biol. 2011;11:1-13. https://doi.org/ 10.1186/1471-2229-11-114.

46. Schnee S, Viret O, Gindro K. Role of stilbenes in the resistance of grapevine to powdery mildew. Physiol Mol Plant Pathol. 2008;72:128-33. https://doi.org/10.1016/j.pmpp.2008.07.002.

47. Chen C-C, Hsu Y-J, Lee T-M, Bax J, Schinkel A, Boersma E, et al. Impact of elevated uric acid on ventricular remodeling in infarcted rats with experimental hyperuricemia. Am J Physiol Heart Circ Physiol. 2011;301:H110717. https://doi.org/10.1152/ajpheart.01071.2010.

48. Roßberg D, Portner J. Erhebungen zur anwendung von pflanzenschutzmitteln im hopfen. J fur Kult. 2015;67:410-6.

49. Julius Kühn-Institut (JKI) I für S und F. Behandlungshäufigkeit. https:// papa.julius-kuehn.de/index.php?menuid=46. Accessed 16 Mar 2021.

50. Wu L, Chen H, Curtis C, Fu ZQ. Go in for the kill: how plants deploy effector-triggered immunity to combat pathogens. Virulence. 2014;5:710-21.

51. Possamai T, Migliaro D, Gardiman M, Velasco R, De Nardi B. Rpv mediated defense responses in grapevine offspring resistant to Plasmopara viticola. Plants. 2020:9:1-10.

52. van Loon LC, Rep M, Pieterse CMJ. Significance of inducible defense-related proteins in infected plants. Annu Rev Phytopathol. 2006;44:135-62.

53. Tao Y, Xie Z, Chen W, Glazebrook J, Chang HS, Han B, et al. Quantitative nature of Arabidopsis responses during compatible and incompatible interactions with the bacterial pathogen pseudomonas syringae. Plant Cell. 2003;15:317-30.

54. Tsuda K, Sato M, Glazebrook J, Cohen JD, Katagiri F. Interplay between MAMP-triggered and SA-mediated defense responses. Plant J. 2008;53:763-75.

55. Langcake L, Lovell PA. Light and electron microscopical studies of the infection ofVitis spp. by Plasmopara viticola, the downy mildew pathogen. Vitis. 1980;19:321-37.

56. Unger S, Büche C, Boso S, Kassemeyer HH. The course of colonization of two different Vitis genotypes by Plasmopara viticola indicates compatible and incompatible host-pathogen interactions. Phytopathology. 2007:97:780-6.

57. Yin L, Li X, Xiang J, Qu J, Zhang Y, Dry IB, et al. Characterization of the secretome of Plasmopara viticola by de novo transcriptome analysis. Physiol Mol Plant Pathol. 2015;91:1-10. https://doi.org/10.1016/j.pmpp. 2015.05.002.

58. Mukhtar MS, McCormack ME, Argueso CT, Pajerowska-Mukhtar KM. Pathogen tactics to manipulate plant cell death. Curr Biol. 2016;26:R60819. https://doi.org/10.1016/j.cub.2016.02.051.

59. Levine A, Tenhaken $\mathrm{R}$, Lamb C. $\mathrm{H}_{2} \mathrm{O}_{2}$ from the oxidative burst orchestrates the plant hypersensitive disease resistance response. Cell. 1994;79:583-93.

60. Tenhaken R, Levine A, Brisson LF, Dixon RA, Lamb C. Function of the oxidative burst in hypersensitive disease resistance. Proc Natl Acad Sci U S A. 1995;92:4158-63.

61. Bove F, Rossi V. Components of partial resistance to Plasmopara viticola enable complete phenotypic characterization of grapevine varieties. Sci Rep. 2020;10:1-12. https://doi.org/10.1038/s41598-020-57482-0.

62. Kortekamp A, Wind R, Zyprian E. Investigation of the interaction of Plasmopara viticola with susceptible and resistant grapevine cultivars. J Plant Dis Prot. 1998;150:475-88.

63. Vezzulli S, Vecchione A, Stefanini M, Zulini L. Downy mildew resistance evaluation in 28 grapevine hybrids promising for breeding programs in Trentino region (Italy). Eur J Plant Pathol. 2018;150:485-95.

64. Zini E, Dolzani C, Stefanini M, Gratl V, Bettinelli P, Nicolini D, et al. R-loci arrangement versus downy and powdery mildew resistance level: a Vitis hybrid survey. Int J Mol Sci. 2019;20:1-29.

65. OIV. Descriptor list for grape varieties and Vitis species (2nd edition). Off Int la Vigne du Vin. http://www.oiv.int/en/technical-standards-anddocuments/description-of-grape-varieties/oiv-descriptor-list-for-grapevarieties-and-vitis-species-2nd-edition.

66. van den Heuvel JFJM, van der Vlugt RAA, Verbeek M, de Haan PT, Huttinga $\mathrm{H}$. Characteristics of a resistance-breaking isolate of potato virus Y causing potato tuber necrotic ringspot disease. Eur J Plant Pathol. 1994;100:347-56

67. Fargette $\mathrm{D}$, Pinel $\mathrm{A}$, Traoré $\mathrm{O}$, Ghesquière $\mathrm{A}$, Konaté $\mathrm{G}$. Emergence of resistance-breaking isolates of rice yellow mottle virus during serial inoculations. Eur J Plant Pathol. 2002;108:585-91. 
68. Ahmed S, de Labrouhe DT, Delmotte F. Emerging virulence arising from hybridisation facilitated by multiple introductions of the sunflower downy mildew pathogen Plasmopara halstedii. Fungal Genet Biol. 2012;49:847-55. https://doi.org/10.1016/j.fgb.2012.06.012.

69. Goodwin SB, Sujkowski LS, Fry WE. Rapid evolution of pathogenicity within clonal lineages of the potato late blight disease fungus. America (NY). 1995;85:669-76.

70. Becker A. Nachhaltige Regionalvermarktung - Wohin geht der Trend? Dtsch Weinmagazin; 2012. p. 24-8.

71. Keller M. Living with other organisms. In: The Science of Grapevines; 2015. p. 343-67.

72. Kennelly MM, Gadoury DM, Wilcox WF, Magarey PA, Seem RC. Seasonal development of ontogenic resistance to downy mildew in grape berries and rachises. Phytopathology. 2005;95:1445-52.

73. Eibach $R$, Töpfer R. Success in resistance breeding: "regent" and its steps into the market. Acta Hortic. 2003;603:687-91.

74. Van der Meer M, Weibel F, Lévite D, Häseli A, Vombach D. Acceptation des vins de cépages résistants par les consommateurs. Rev Suisse Vitic Arboric Hortic. 2010;42:147-50.

75. Casanova-Gascón J, Ferrer-Martín C, Bernad-Eustaquio A, Elbaile-Mur A, Ayuso-Rodríguez JM, Torres-Sánchez S, et al. Behavior of vine varieties resistant to fungal diseases in the Somontano region. Agronomy. 2019;9:1-15.

76. Merz PR, Moser T, Höll J, Kortekamp A, Buchholz G, Zyprian E, et al. The transcription factor $\mathrm{V} v W R K Y 33$ is involved in the regulation of grapevine
(Vitis vinifera) defense against the oomycete pathogen Plasmopara viticola. Physiol Plant. 2015;153:365-80.

77. Hood ME, Shew HD. Applications of $\mathrm{KOH}$-aniline blue flourescence in the study of plant-fungal interactions. Am Phytopathol Soc. 1996;86:704-8.

78. Koch E, Slusarenko A. Arabidopsis is susceptible to infection by a downy mildew fungus. Plant Cell. 1990;2:437-45.

79. Schindelin J, Arganda-Carreras I, Frise E, Kaynig V, Longair M, Pietzsch T, et al. Fiji: an open-source platform for biological-image analysis. Nat Methods. 2012;9:676-82.

80. Daudi A. O'Brien JA. Detection of hydrogen peroxide by DAB staining in Arabidopsis leaves. Bio Protoc. 2012;18:1-4.

81. Höll J, Vannozzi A, Czemmel S, Donofrio C, Walker AR, Rausch T, et al. The R2R3-MYB transcription factors MYB14 and MYB15 regulate stilbene biosynthesis in Vitis vinifera. Plant Cell. 2013;25:4135-49.

82. Lorenz DH, Eichhorn KW, Bleiholder H, Klose R, Meier U, Weber E. Growth stages of the grapevine: Phenological growth stages of the grapevine (Vitis vinifera L. ssp. vinifera) — codes and descriptions according to the extended BBCH scale †. Aust J Grape Wine Res. 1995;1:100-10.

83. European and Mediterranean Plant Protection Organization. Guideline for the Efficacy Evaluation of Fungicides. EPPO Bull. 2000;P 1/31(3):1-3.

\section{Publisher's Note}

Springer Nature remains neutral with regard to jurisdictional claims in published maps and institutional affiliations.
Ready to submit your research? Choose BMC and benefit from:

- fast, convenient online submission

- thorough peer review by experienced researchers in your field

- rapid publication on acceptance

- support for research data, including large and complex data types

- gold Open Access which fosters wider collaboration and increased citations

- maximum visibility for your research: over 100M website views per year

At BMC, research is always in progress.

Learn more biomedcentral.com/submissions 